\title{
Cholesterol Granuloma of Hydrocele Sac Mimicking Testicular Tumour
}

\author{
Nehal Ahmad ${ }^{1}$, Sabina Khan ${ }^{1 *}$, Mohammad Jaseem Hasan', Sujata Jetley ${ }^{1}$ and Abhinav Jain ${ }^{2}$ \\ ${ }^{1}$ Department of Pathology, Hamdard Institute of Medical Sciences and Research, Jamia Hamdard, New Delhi, India \\ ${ }^{2}$ Department of Radiodiagnosis, Hamdard Institute of Medical Sciences and Research, Jamia Hamdard, New Delhi, India
}

\section{ABSTRACT}

Cholesterol granuloma is a rare inflammatory granulation tissue that occurs in response to the deposition of cholesterol crystals. It is found most commonly in the paranasal sinuses or temporal bones, but there are also rare reports of their occurrence in other sites also. Here we report a rare case of cholesterol granuloma of hydrocele sac in a 59 year old man who presented with non tender right scrotal swelling. Patient was operated for vaginal hydrocele which on histopathological examination revealed cholesterol granuloma which is very rare in these sites. It can be very difficult to preoperatively distinguish testicular tumours from cholesterol granulomas of the testis or epididymis. Therefore, cholesterol granuloma should be kept in mind in patients with large and non-tender scrotal masses.

Keywords: Cholesterol granuloma, Tunica vaginalis, Hydrocele

\section{Introduction}

Cholesterol granulomas are a type of non-specific inflammatory reaction to the presence of a foreign body such as cholesterol crystals ${ }^{[1]}$. They are found most commonly in the paranasal sinuses or temporal bones, but there are also rare reports of their occurrence in the testicular and epididymal sites as well as other sites like peritoneum, parotid gland, lymph nodes, thyroglossal duct, kidney, liver, and spleen ${ }^{[2,3]}$. These testicular and epididymal lesion may simulate an intrascrotal tumor on physical examination, on ultrasound and at operation. This lesion might be caused by trauma and inflammation.

Here we describe a rare incidental case of cholesterol granuloma of hydrocele sac which presented as long standing scrotal swelling simulating a tumour on physical examination and ultrasound.

\section{Case Report}

A 59-year-old man came to our surgery OPD with complain of right scrotal swelling that had been present for five years. The patient was apparently asymptomatic with no signs of fever or acute infection. Mild scrotal discomfort was present. His past medical history was irrelevant; the patient was not hypercholesterolemic. The patient denied any history of known scrotal trauma. Laboratory studies including a complete blood count profile, basic biochemical profile, and urinalysis were all within normal ranges. The patient's medical history was unremarkable with respect to tuberculosis, sarcoidosis, syphilis, and fungal infections. Physical examination revealed a $10.5-\mathrm{cm}$ tense cystic, non-tender scrotal swelling, testes was not palpable separately and transillumination was negative. A scrotal ultrasonography revealed turbid scrotal sac fluid with few echogenic areas and scrotal wall thickening. Surgery was performed for right vaginal hydrocele. At operation yellowish turbid fluid along with the thick sac was found. A partial resection of tunica vaginalis was performed, sparing the testis. A histopathological examination revealed mostly fibrocollagenous tissue, mixed inflammatory infiltrate consisting of lymphocytes, and few histiocytes, eosinophils along with presence of numerous cholesterol crystals, multinucleated foreign body giant cells. Based on these findings, the final diagnosis of a cholesterol granuloma of hydrocele sac was rendered.

\section{Discussion}

Cholesterol granuloma is a fibrogranulomatous lesion which forms in response to foreign-body giant cell reaction to cholesterol crystals ${ }^{[2-4]}$. It can develop in any region of the body where cholesterol crystal deposition may occur, and is a well-recognised lesion affecting the facial skeleton, skull and middle ear ${ }^{[5]}$. It was first reported in 1894 in middle-ear disease ${ }^{[6]}$. They have been described with less frequency in the kidneys, breast, peritoneum, mediastinum, parotid gland, lung, liver, spleen and testis. In our case it was seen in the testis ${ }^{[2,3,7]}$. The clinical presentation is variable and may be encountered incidentally or present due to space occupying effects on surrounding structures ${ }^{[2,5]}$.

The cholesterol crystals stimulate a foreign-body type giant cell reaction that is responsible for the granuloma formation ${ }^{[3,5,7]}$. Although the exact pathogenesis of cholesterol 


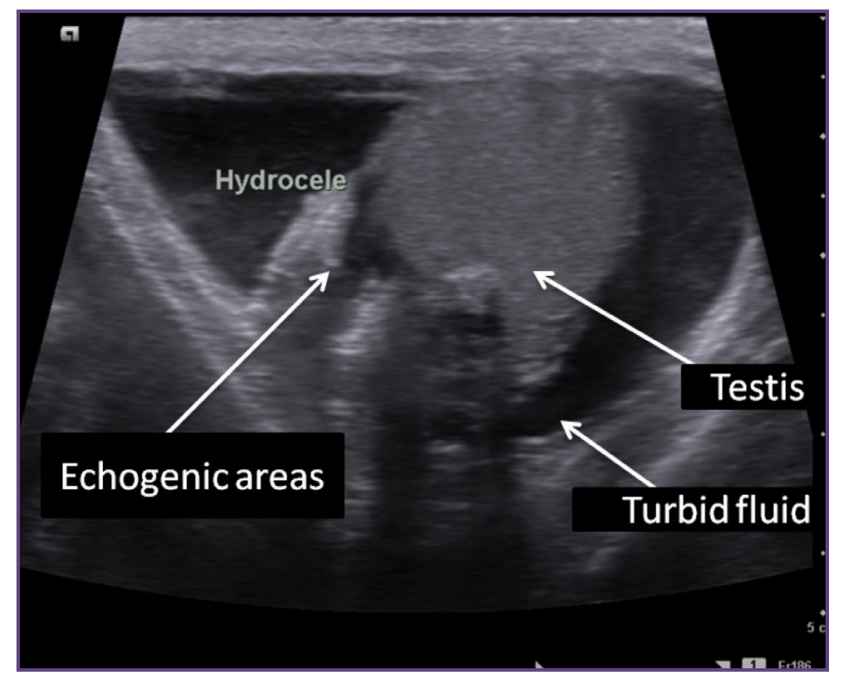

Fig . 1: High frequency Ultrasound image obtained with a $12 \mathrm{MHz}$ linear transducer reveals turbid scrotal sac fluid with few echogenic areas and scrotal wall thickening. The testis and epididymis were normal on detailed scan.

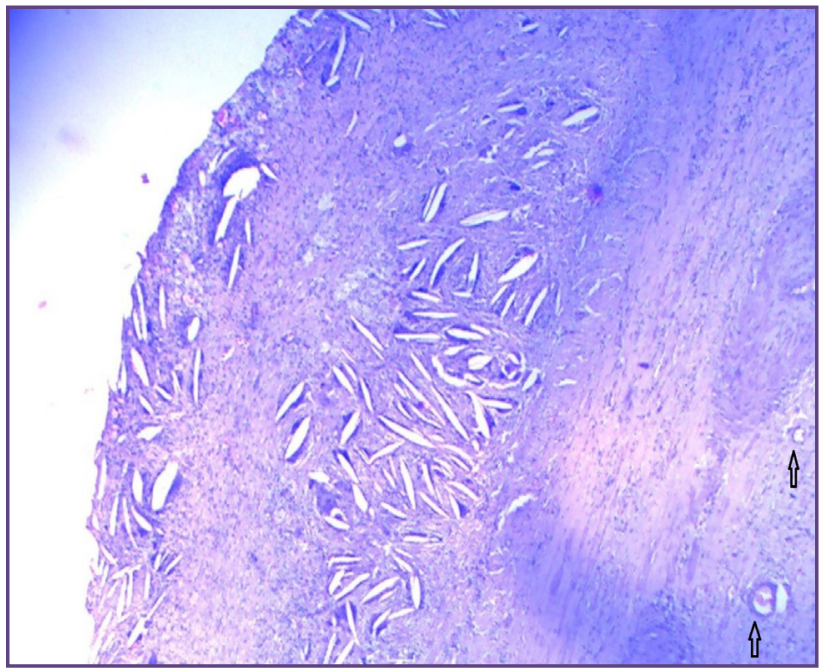

Fig . 2 : Photomicrograph showing numerous cholesterol clefts and few epididymal glands (arrows) (H\&E stain, $4 \mathrm{x}$ )

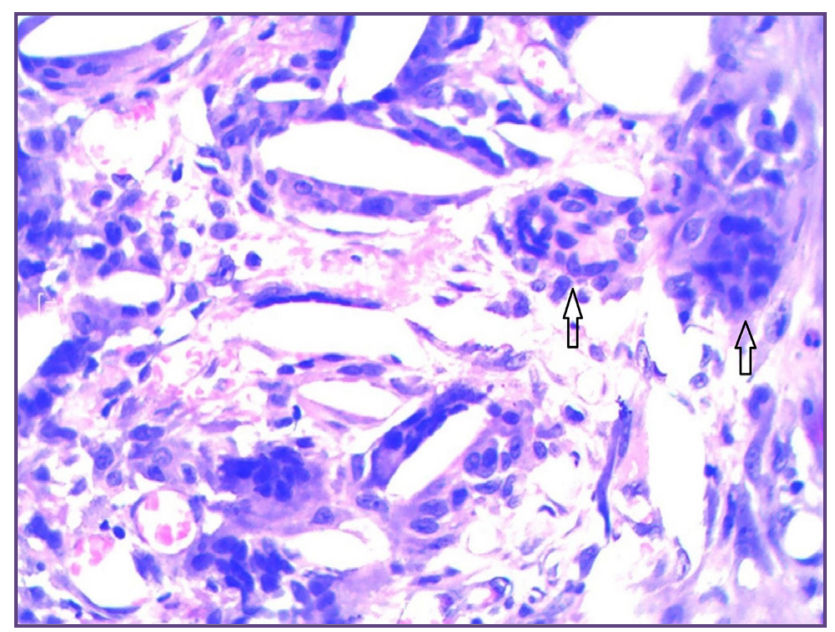

Fig. 3 : Photomicrograph showing numerous cholesterol clefts, giant cells (arrows) and inflammatory cells comprising of lymphocytes, histiocytes, plasma cells and occasional eosinophils. (H\&E Stain, 40x).

granuloma is unknown, it is believed that a non-infectious local reaction induces ischemic necrosis, granulomatous reaction, and scarring. It has been suggested that the source of cholesterol can be derived from degenerated cells during the inflammatory process and haemolysis or as a transudate from serum ${ }^{[2,3]}$. The presence of cholesterol crystals results in a foreign body reaction involving inflammatory cells and granulomatous tissue finally develops ${ }^{[8,9]}$.

Histologically cholesterol granuloma consists of extensive granulation tissue with dense masses of cholesterol clefts surrounded by multinucleated giant cells, hemosiderinladen macrophages, lymphocytes and plasma cells ${ }^{[2,3,7]}$.
This characteristic appearance has been described to be diagnostic of cholesterol granuloma which was also seen in our case ${ }^{[7]}$.

There are characteristic features identified on imaging that may reflect a cholesterol granuloma, however surgical excision is required to enable histopathological analysis and diagnostic confirmation.

There are very few cases of cholesterol granuloma of hydrocele sac reported in the literature. Farina Perez LA and collegues reported a case of Hydrocele and cholesterol granuloma of the tunica vaginalis simulating a tumor in echography in $1998^{[10]}$. Jain I. Lin and collegues reported 
a case of cholesterol granuloma of right testis in 1979 and emphasized the difference from lipogranuloma ${ }^{[11]}$. S. B. Lowenthal and collegues also reported a case of cholesterol granuloma of the tunica vaginalis simulating a testicular tumor ${ }^{[12]}$. In a study in 2009 it was reported that cholesterol granuloma of the testis is indistinguishable from carcinoma of the testis ${ }^{[1]}$. They concluded that if in doubt, surgical exploration and histopathologic examination are absolutely necessary. Similarly in our case the excised tissue was sent for histopathological examination. Macroscopically the mass originated from the tunica vaginalis and was a cystic lesion with a thick fibrous capsule of the sac. The cystic lesion was filled with dark yellowish brown material. Microscopically, the sections showed fibrogranulomatous tissue containing innumerable cholesterol clefts and numerous foreign body giant cells. The histological diagnosis was Cholesterol granuloma of hydrocele sac.

Management of cholesterol granuloma is largely directed by the location, size and presentation of the lesion ${ }^{[2-5]}$.

\section{Conclusion}

In conclusion, cholesterol granuloma of the hydrocele sac is an extremely rare benign condition. They often remain asymptomatic and are discovered incidentally on imaging or intra-operatively. Given that it is a benign and curable lesion, early recognition and management is important, and because it can mimic a malignant neoplasm, surgical resection should be considered.

\section{Reference}

1. Lam CY, Lin CM, Tsai SW, et al. Cholesterol granuloma of the epididymis mimicking a paratesticular tumor. JTUA 2009; 20: 89-91.
2. Luckraz H, Coulston J, Azzu A. Cholesterol granuloma of the superior mediastinum. Ann Thorac Surg 2006; 81: 1509-10.

3. Fujimoto K, Takamori S, Yano H, Sadohara J, Matsuo T, Terazaki Y, et al. Focal cholesterol granuloma in the anterior mediastinum. J Thorac Oncol 2007; 2: 1054-6.

4. Gore M, Zanation A, Ebert C, Senior B. Cholesterol granuloma of the petrous apex. Otolaryngol Clin North Am 2011; 44: 1043-58.

5. Nikolaidis V, Malliari H, Psifidis D, Metaxas S. Cholesterol granuloma presenting as a mass obstructing the external ear canal. BMC Ear Nose Throat Disord 2010; 10: 4.

6. Manasse P. Ueber Granulationsgeshwulst mit Fremdkoerriesenzellen. Virchows Arch 1894; 136: 245

7. Leon M, Chavez C, Fyfe B, Nagorsky M, Garcia F. Cholesterol granuloma of the maxillary sinus. Arch Pathol Lab Med. 2002; 126: 217-9.

8. Nistal M, Mate A, Paniagua R. Granulomatous epididymal lesion of possible ischemic origin. Am J Surg Pathol 1997; 21: 951-6.

9. Spajic B, Cupic H, Stimac G, et al. Cholesterol granuloma of the right epididymis mimicking an acute scrotum. Asian J Androl 2006; 8: 749-50

10. Fariña Pérez LA, Menéndez P, Macho V. Hydrocele and cholesterol granuloma of the tunica vaginalis simulating a tumor in echography. Actas Urol Esp. 1998 Jan; 22(1): 70-3.

11. Lin JI, Tseng CH, Marsidi PJ, Bais VC. Cholesterol granuloma of right testis; Urology 1979 ; 14(5): 522-523

12. Lowenthal SB, Goldstein AMB, Terry R. Cholesterol granuloma of tunica vaginalis simulating testicular tumor. Urology July 1981; 18(1): 89-90

*Corresponding author:

Dr Sabina Khan. Associate Professor, Department of Pathology, Hamdard Institute of Medical Sciences and Research,

Jamia Hamdard, New Delhi 110062, India

Phone: +91 9540248289

Email: drsabina1@gmail.com

Date of Submission : 29.09.2016

Financial or other Competing Interests: None. 